Tropical Journal of Pharmaceutical Research February 2017; 16 (2): 287-296

ISSN: $1596-5996$ (print); 1596-9827 (electronic)

(C) Pharmacotherapy Group, Faculty of Pharmacy, University of Benin, Benin City, 300001 Nigeria.

All rights reserved.

Available online at http://www.tjpr.org

Original Research Article

http://dx.doi.org/10.4314/tjpr.v16i2.5

\title{
In vitro and in vivo evaluation of alginate and alginate- chitosan beads containing metformin hydrochloride
}

\author{
Behzad Mokhtare ${ }^{1}$, Meltem Cetin ${ }^{1 \star}$, Rukiye Sevinc Ozakar ${ }^{1}$ and Hatice \\ Bayrakceken $^{2}$ \\ ${ }^{1}$ Department of Pharmaceutical Technology, Faculty of Pharmacy, ${ }^{2}$ Department of Chemical Engineering, Faculty of \\ Engineering, Ataturk University, Erzurum, Turkey
}

*For correspondence: Email: melcetin@atauni.edu.tr; melcetin@hotmail.com; Tel: +90 4422315236

Received: 6 August 2015

Revised accepted: 15 October 2016

\begin{abstract}
Purpose: To prepare metformin HCl-loaded alginate (AL) and alginate-chitosan (AL-CS) beads for oral application and to evaluate their in vitro characteristics and in vivo activities.

Methods: AL and AL-CS beads were prepared using ionotropic gelation. The beads were evaluated for particle size, surface morphology, drug encapsulation efficiency (EE) and in vitro drug release. The antidiabetic effects of the beads were evaluated in diabetic Sprague Dawley rats.

Results: The mean particle sizes of AL and AL-CS beads in wet state ranged from $1714 \pm 140$ to 1850 $\pm 103 \mu \mathrm{m}$. The EE \% of AL and AL-CS beads were $33.58 \pm 1.56$ and $24.11 \pm 1.72$, respectively, with sustained in vitro drug release of about 93 to $96 \%$ within 8 days in phosphate buffer (PB). Optimized metformin HCl-loaded AL and AL-CS beads showed significant hypoglycaemic effects in diabetic rats over a prolonged period (about $12 \mathrm{~h}$ ) after oral administration compared to the pure drug $(p<0.05)$.

Conclusion: Metformin HCl-loaded AL and AL-CS beads for oral application may be useful in prolonging the hypoglycaemic effect of metformin. This is capable of increasing patients' compliance to the medication.
\end{abstract}

Keywords: Alginate, Beads, Chitosan, Metformin, Diabetes, In vivo study

Tropical Journal of Pharmaceutical Research is indexed by Science Citation Index (SciSearch), Scopus, International Pharmaceutical Abstract, Chemical Abstracts, Embase, Index Copernicus, EBSCO, African Index Medicus, JournalSeek, Journal Citation Reports/Science Edition, Directory of Open Access Journals (DOAJ), African Journal Online, Bioline International, Open-J-Gate and Pharmacy Abstracts

\section{INTRODUCTION}

Metformin hydrochloride is a biguanide derivative widely used for the treatment of Type 2 diabetes, and prescribed for about 120 million people worldwide [1-4]. Metformin is recommended by the European Association for the Study of Diabetes, and the American Diabetes Association as the first line therapy for Type 2 diabetes [2,3]. Following oral administration, the drug is mainly absorbed from the upper small intestine, and has a relatively low bioavailability (absolute bioavailability of metformin is about 50 to $60 \%)$. Its biological half-life $\left(\mathrm{t}_{1 / 2}\right)$ is in the range of $0.9-2.6 \mathrm{~h}$. Therefore, repeated applications of high doses of the medicine are needed for effective treatment. As a result, patient compliance is reduced and/or the incidence of side effects such as diarrhoea, nausea, anorexia, vomiting, weight loss, and taste disturbance are increased [1,5]. Moreover, lactic acidosis, which is sometimes fatal, has occurred with biguanides [1]. Its incomplete absorption is improved by using convenient drug delivery systems such as bio-adhesive and gastro-retentive drug delivery systems [6,7]. In addition, the development of different types of formulation for metformin is necessary for reduction of dosing frequency of the drug and its gastrointestinal side effects [8]. 
Sodium alginate, a salt of alginic acid, is a natural, polyanionic, non-toxic water-soluble copolymer of $\alpha$-L-gluronic acid and $\beta$-Dmannuronic acid residues. It is obtained from marine brown algae and has the ability to form a gel network in the presence of divalent cations such as calcium in aqueous media. Thus, alginate beads are successfully prepared by ionotropic gelation $[9,10]$. More effective beads for the controlled release of drugs can be prepared using the combination of chitosan and alginate. The poly-electrolyte complex is formed with the ionic interaction between the amino residues of chitosan and the carboxyl residues of alginate [10]. The addition of chitosan in the formulation alters the diffusion rate of the encapsulated drugs and causes the bulk modification of the alginate bead structure [11]. CS is a polysaccharide obtained by the deacetylation of chitin found in the exoskeleton of crustaceans (e.g. crab and shrimp) $[12,13]$. It has cationic character due to its primary amino groups and thus, shows muco-adhesive properties. AL beads and CS beads containing metformin $\mathrm{HCl}$ were prepared in previous studies $[14,15]$. In our study, besides metformin $\mathrm{HCl}$ loaded $\mathrm{AL}$ beads, we also prepared AL-CS beads containing metformin $\mathrm{HCl}$ using $\mathrm{AL}$ and CS combination. CS and AL are very useful in pharmaceutical applications and they are the most widely used hydrogels in the preparation of sustained release dosage forms $[11,15,16]$.

The present study focuses on the development and in vitro characterization of metformin $\mathrm{HCl}$ loaded $\mathrm{AL}$ beads and AL-CS beads. It also focuses on in vivo evaluation of the hypoglycaemic activities of the bead formulations in streptozotocin (STZ) and nicotinamide-induced diabetic rats.

\section{EXPERIMENTAL}

\section{Materials}

Metformin $\mathrm{HCl}$ was a generous gift from Sandoz llac Sanayi \& Ticaret AS (Istanbul, Turkey). Sodium Alginate, STZ, nicotinamide and calcium chloride were obtained from Sigma-Aldrich (USA), and chitosan (Protosan UP CL 113) was purchased from FMC BioPolymer (Norway). All other chemicals and reagents were of analytical grade and used as they were received.

\section{Preparation of metformin $\mathrm{HCl}$-loaded $\mathrm{AL}$ and AL-CS beads}

Metformin $\mathrm{HCl}$-loaded $\mathrm{AL}$ and $\mathrm{AL}-\mathrm{CS}$ beads were prepared by ionotropic gelation technique.
Metformin $\mathrm{HCl}$ (100 mg) was dissolved in a sodium alginate aqueous solution $(10 \mathrm{~mL} ; 2 \%$ $w / v$ ). AL-drug solution (bubble-free) was dropped through a 26-gauge syringe needle into $15 \%(\mathrm{w} / \mathrm{v})$ of calcium chloride solution on magnetic stirrer at $700 \mathrm{rpm}$ for $15 \mathrm{~min}$ [17]. The formed beads were further mixed in gelling medium at room temperature. After filtration, the beads were lyophilized for $24 \mathrm{~h}$.

In addition, the AL-CS beads were also prepared by ionotropic gelation technique. Metformin $\mathrm{HCl}$ (100 mg) was dissolved in a sodium alginate aqueous solution ( $10 \mathrm{~mL} ; 2 \% \mathrm{w} / \mathrm{v})$. The solution was dropped through a 26-gauge syringe needle into $5 \%(\mathrm{w} / \mathrm{v})$ of calcium chloride solution $(\mathrm{pH}$ adjusted to 4.5$)$ containing chitosan $(0.5 \%$, w/v) on magnetic stirrer at $700 \mathrm{rpm}$ for $15 \mathrm{~min}$. The resultant AL-CS beads were further mixed in gelling medium at room temperature $[18,19]$. After filtration, the beads were also lyophilized for $24 \mathrm{~h}$.

\section{Surface morphology and bead size}

The surface morphology and shape evaluation of the bead formulations were examined by Scanning Electron Microscope (SEM; Inspect S50, FEI, USA) (used for lyophilized beads) and digital photographs (used for wet beads). The size of wet beads was determined by Vernier callipers.

\section{Drug content of the beads}

Lyophilized beads $(20 \mathrm{mg})$ in $20 \mathrm{~mL}$ of PB $(\mathrm{pH}$ 6.8) in amber-coloured vials were sonicated for $15 \mathrm{~min}$ and mixed at $750 \mathrm{rpm}$ for $4 \mathrm{hr}$ in the dark for complete extraction of metformin $\mathrm{HCl}$. The dispersion was then centrifuged at $5000 \mathrm{rpm}$ for $15 \mathrm{~min}$ at $15^{\circ} \mathrm{C}$. The drug content of the supernatant of each sample was then measured using a validated UV method at $232 \mathrm{~nm}$ [20]. The experiment was performed in triplicate.

\section{In vitro release studies}

An incubation method was used for the investigation of metformin $\mathrm{HCl}$ release from beads in both media (PB, pH 6.8 and $\mathrm{HCl}, \mathrm{pH}$ 1.2). Lyophilized beads ( $20 \mathrm{mg}$ ) were suspended in $20 \mathrm{~mL}$ of $\mathrm{PB}(\mathrm{pH} \mathrm{6.8)}$ or $\mathrm{HCl}(\mathrm{pH} 1.2)$ in amber-colored vials and then immersed in a constant temperature $\left(37^{\circ} \mathrm{C}\right)$ water bath. At predetermined time intervals, samples $(3 \mathrm{~mL})$ were withdrawn from the release medium and replaced with the same volume of fresh buffer. All samples were centrifuged at $12500 \mathrm{rpm}$ for 10 min, and their drug contents were measured using a validated UV method at $232 \mathrm{~nm}$ (for PB 
$\mathrm{pH}$ 6.8) and $209 \mathrm{~nm}$ (for $\mathrm{HCl} \mathrm{pH}$ 1.2) [20]. The experiment was performed in triplicate.

\section{FT-IR analysis}

A Perkin-Elmer Spectrum One model FT-IR was used to record the IR spectra of $A L, C S$, metformin $\mathrm{HCl}$, blank and metformin $\mathrm{HCl}$-loaded beads prepared in $\mathrm{KBr}$ disks in the region of $4000-400 \mathrm{~cm}^{-1}$.

\section{In vivo studies}

The animal experiments were conducted according to the ethical norms approved by the Ethics Committee of Ataturk University (May 31 2013, No: 38). Fifty-nine male Sprague-Dawley rats (weighing $180-250 \mathrm{~g}$ ) were obtained from the Experimental Animal Teaching and Research Center of the Experimental Animal Laboratory at Ataturk University. The rats were maintained on a normal diet and drinking water ad libitum at 24 $\pm 2{ }^{\circ} \mathrm{C}$ and under a $12 \mathrm{~h}$ light/dark cycle.

\section{Analysis of fasting serum insulin levels}

The basal blood glucose levels of overnightfasted animals were determined using a glucometer (On.Call ${ }^{\circledR}$ Plus, Acon Lab, Inc, USA). Thereafter, diabetes was induced in the rats by administering a single intraperitoneal (i.p.) injection of freshly-prepared streptozotocin (STZ, $40 \mathrm{mg} / \mathrm{kg}$ body weight (b.w.)) in cold citrate buffer (pH 4.5). After $15 \mathrm{~min}$, the rats were given freshly prepared nicotinamide solution i.p. (120 mg/kg b.w) [21]. Diabetes was confirmed in the rats by measuring blood glucose levels on day 7 of the induction. Animals with fasting blood glucose higher than $126 \mathrm{mg} / \mathrm{dL}$ were considered to be diabetic. The blood samples of diabetic rats $(n=$ 8) collected from the tail veins were centrifuged $(10,000 \mathrm{rpm}, 10 \mathrm{~min})$ and the supernatant was frozen until assayed for fasting serum insulin level using rat insulin enzyme immunoassay kit (SPI-BIO Bertin Pharma, France). The serum samples of control rats (healthy rats; $n=8$ ) were also analysed for fasting insulin level [21-23].

\section{Evaluation of hypoglycaemic activity of beads in STZ-nicotinamide -induced diabetic rats}

The rats were divided into six different groups as follows:

Group I: Control rats (healthy rats; $n=6$ ) Group II: Diabetic control $(n=8)$
Group III: Diabetic rats treated with pure metformin $\mathrm{HCl}(100 \mathrm{mg} / \mathrm{kg} \mathrm{b.w})(\mathrm{n}=6)$

Group IV: Diabetic rats treated with blank beads $(\mathrm{n}=8)$

Group V: Diabetic rats treated with metformin $\mathrm{HCl}$-loaded AL-CS beads (equivalent to metformin $\mathrm{HCl} 100 \mathrm{mg} / \mathrm{kg}$ b.w.) $(\mathrm{n}=9)$

Group VI: Diabetic rats treated with metformin $\mathrm{HCl}$-loaded $\mathrm{AL}$ beads (equivalent to metformin $\mathrm{HCl} 100 \mathrm{mg} / \mathrm{kg}$ b.w.) $(\mathrm{n}=6)$

Type-2 diabetes was induced and controlled as described above. Diabetic rats were divided randomly into five different groups (Group IIGroup VI).The pure drug and the formulations of blank and metformin $\mathrm{HCl}$-loaded beads were administered orally through a flexible plastic tube after an overnight fast. Fasting blood samples were collected through the tail vein of the rats at onset, then on the $2^{\text {td }}, 3^{\text {rd }}, 4^{\text {th }}, 6^{\text {th }}, 8^{\text {th }}$ and $12^{\text {th }} \mathrm{hr}$ after the treatment, and analysed for glucose using a glucometer. Changes in body weight for all experimental rats were monitored. The rats remained fasted throughout the experiment, but were allowed free access to water.

\section{Statistical analysis}

The experimental data are expressed as mean \pm SD. Statistical evaluations were performed using Mann-Whitney $U$ test (SPSS Statistics 20.0 program; SPSS Inc, IL, USA). $P<0.05$ was taken as indicative of statistical significance.

\section{RESULTS}

The SEM images and the digital photographs of metformin $\mathrm{HCl}$-loaded $\mathrm{AL}$ and $\mathrm{AL}-\mathrm{CS}$ beads (in dry and wet state, respectively) were shown in Figure 1. They were spherical in the wet state (Figure $1 \mathrm{~b}$ and $1 \mathrm{~d}$ ). The values for particle size (in wet state) and EE \% of all bead formulations are summarized in Table 1 while the in vitro drug release profiles were given in Figure 2 . Regardless of the release medium, about 25 $40 \%$ of the loaded metformin HCL was released from the beads during the initial burst release $(60$ min). In addition, more than $93 \%$ of the drug was released from both formulations in both media within 8 days (Figure 2).

The FT-IR spectra of metformin $\mathrm{HCl}, \mathrm{AL}, \mathrm{CS}$, and all bead formulations are presented in Figure 3 and Figure 4. 


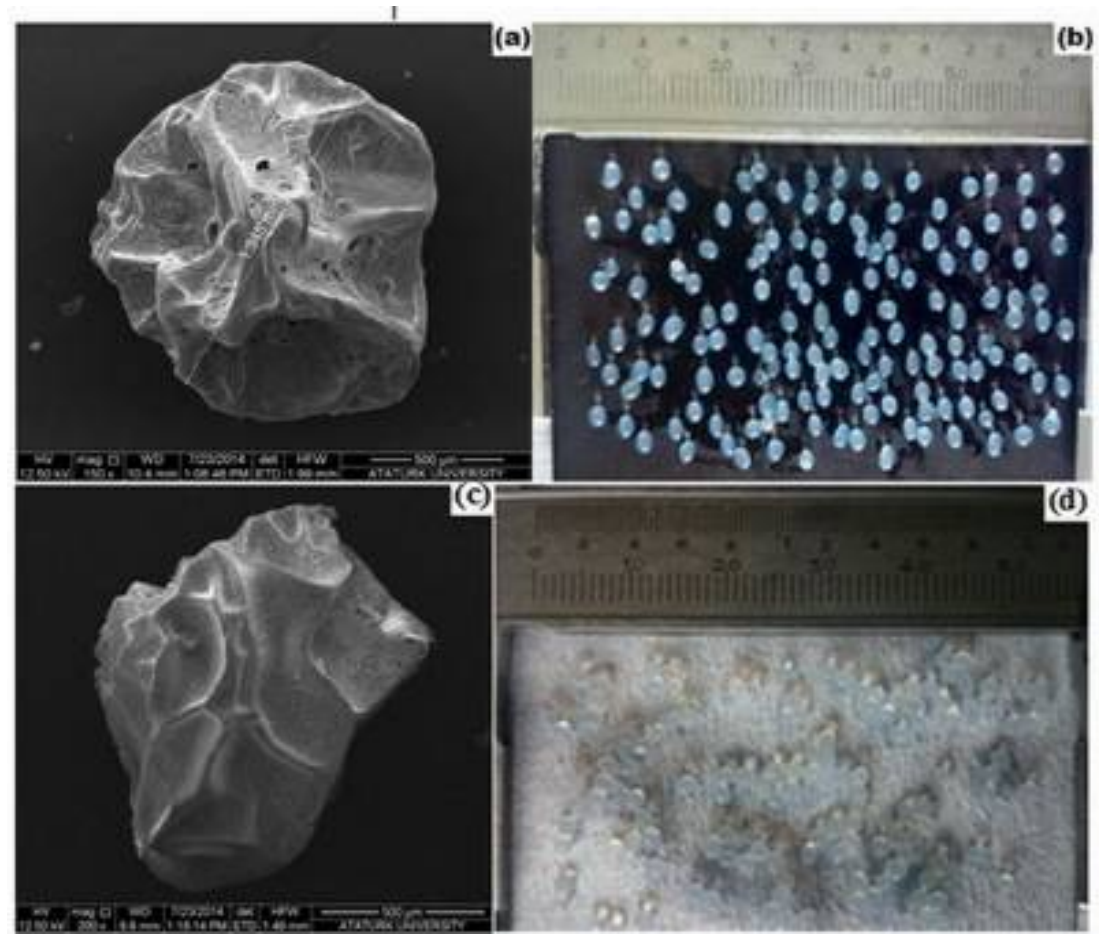

Figure 1: Scanning Electron Microscope (SEM) images (a and c) and digital photographs (b and d), of metformin $\mathrm{HCl}$-loaded-alginate and alginate-chitosan beads respectively

Table 1: Particle size, encapsulation efficiency (EE) and drug loading (DL) of beads (mean \pm SD)

\begin{tabular}{lccc}
\hline Formulation & $\begin{array}{c}\text { Mean particle size }(\boldsymbol{\mu m}, \\
\mathbf{n = 3 6 )}\end{array}$ & EE (\%, $\mathbf{n = 3})$ & DL (\%, $\mathbf{n = 3})$ \\
\hline Blank AL beads & $1742 \pm 105$ & - & - \\
Blank AL-CS beads & $1714 \pm 140$ & - & - \\
Metformin HCl loaded-AL & $1850 \pm 103$ & $33.58 \pm 1.56$ & $1.98 \pm 0.08$ \\
beads & $1733 \pm 60$ & $24.11 \pm 1.72$ & $4.55 \pm 0.28$ \\
Metformin HCl & loaded-AL-CS beads &
\end{tabular}

$A L=$ alginate; $A L-C S=$ alginate-chitosan

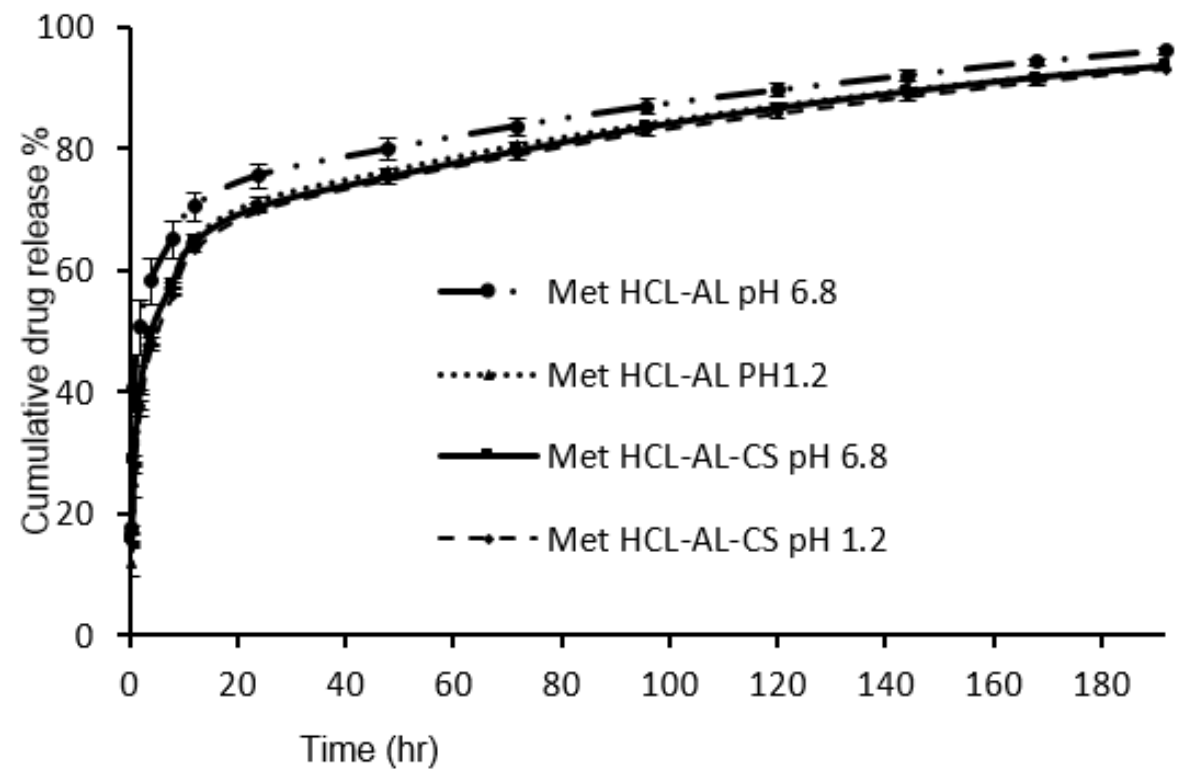

Figure 2: Release profiles of alginate and alginate-chitosan beads in $\mathrm{HCl}(\mathrm{pH} \mathrm{1.2)}$ and phosphate buffer $(\mathrm{pH} 6.8)$. Values are mean \pm SD $(n=3)$ 
The FT-IR spectrum of AL polymer showed peaks at $3662.30 \mathrm{~cm}^{-1}$ due to O-H stretching, at $2971.71 \mathrm{~cm}^{-1}$ because of aliphatic $\mathrm{C}-\mathrm{H}$ stretching, at $1406.38 \mathrm{~cm}^{-1}$ due to symmetric and asymmetric carboxylate salt groups stretching, at $1066.01 \mathrm{~cm}^{-1}$ related to $\mathrm{C}-\mathrm{O}$ stretching, and at $889.51 \mathrm{~cm}^{-1}$ due to $\mathrm{C}-\mathrm{C}$ and $\mathrm{C}-\mathrm{C}-\mathrm{H}$ stretching (Figure 3) [24]. The spectrum of metformin $\mathrm{HCl}$ displayed peaks at $3367.79 \mathrm{~cm}^{-1}(\mathrm{~N}-\mathrm{H}$ asymmetric stretching), at $3293.10 \mathrm{~cm}^{-1}$ and $3149.27 \mathrm{~cm}^{-1}(\mathrm{~N}-\mathrm{H}$ symmetric stretching), at $1621.90 \mathrm{~cm}^{-1}$ ( $\mathrm{C}=\mathrm{N}$ stretching), at $1557.70 \mathrm{~cm}^{-1}$ ( $\mathrm{N}-\mathrm{H}$ bending in plane), at $1472.57 \mathrm{~cm}^{-1}$, at $1447.01 \mathrm{~cm}^{-1}$ and $1417.93 \mathrm{~cm}^{-1}(\mathrm{C}-\mathrm{H}$ asymmetric bending; - $\mathrm{CH} 3$ ), at $1166.68 \mathrm{~cm}^{-1}$ and 1061.30 $\mathrm{cm}^{-1}$ (C-N stretching), at $936.41 \mathrm{~cm}^{-1}$ and 735.82 $\mathrm{cm}^{-1}$ (N-H wagging), at $632.29 \mathrm{~cm}^{-1}\left(\mathrm{NH}_{2}\right.$ rocking) and also at 550.02, $530.34 \mathrm{~cm}^{-1}$ (C-N-C bending) (Figure 3) $[25,26]$. Besides, the spectrum of CS presented peaks at $3232.49 \mathrm{~cm}^{-1}$ assigned to $\mathrm{NH}_{2}$ and $\mathrm{O}-\mathrm{H}$ stretching, at $2879.55 \mathrm{~cm}^{-1}$ because of $\mathrm{C}-\mathrm{H}$ stretching $\left(\mathrm{CH}_{2}\right)$, at $1616.78 \mathrm{~cm}^{-1}$ attributed to $\mathrm{C}=\mathrm{O}$ stretching, at $1146.85 \mathrm{~cm}^{-1}$ due to bridge-O stretching, at $1032.16 \mathrm{~cm}^{-1}$ and $1060.13 \mathrm{~cm}^{-1}$ assigned to $\mathrm{C}-\mathrm{O}$ stretching, and at $1373.42 \mathrm{~cm}^{-1}$ due to NHCO stretching (Figure 3) [27-29]. In the spectrum of metformin $\mathrm{HCl}$ loaded AL beads, the bands in $2987.66 \mathrm{~cm}^{-1}$, $2896.93 \mathrm{~cm}^{-1}, 1417.25 \mathrm{~cm}^{-1}, 642.27 \mathrm{~cm}^{-1}$ related to the presence of metformin $\mathrm{HCl}$ were observed compared to the spectrum of blank AL beads (Figure 4). Besides, the spectrum of AL-CS beads containing drug showed that the intensity of the peaks attributed to vibrations in the spectrum of drug $\left(3369.83 \mathrm{~cm}^{-1}, 2988.71 \mathrm{~cm}^{-1}\right.$, $1626.76 \mathrm{~cm}^{-1}, 1066.09 \mathrm{~cm}^{-1}$ ) increased and also bands were observed at $937.58 \mathrm{~cm}^{-1}$ and 732.86 $\mathrm{cm}^{-1}$ (Figure 4). The FT-IR spectra of drug-loaded beads confirmed the presence of metformin $\mathrm{HCl}$ in both bead formulations.

The fasting serum insulin levels of control rats and diabetic rats with fasting blood glucose level of higher than $126 \mathrm{mg} / \mathrm{dL}$ were found to be 0.66 $\pm 0.09 \mathrm{ng} / \mathrm{mL}$ and $0.51 \pm 0.15 \mathrm{ng} / \mathrm{mL}$, respectively. The reduction of fasting blood glucose level (as percentage of basal levels) after the administration of pure drug, and bead formulations versus time curves are given in Figure 5. The fasting blood glucose concentration of Group II was higher than that of Group I $(p<0.05$; Figure 5). Hypoglycaemic effect obtained for Groups V and VI were significantly different from that of Group III ( $p<0.05$; except at 3 and $4 \mathrm{hr}$ for Group V, and $4 \mathrm{hr}$ for Group VI). However, there was no a significant difference between the hypoglycaemic effects of both bead formulations $(p>0.05)$.

\section{DISCUSSION}

The results obtained in this study showed that the presence of chitosan in bead formulation had no significant effect on the size and drug content of the beads. Besides, the $\mathrm{pH}$ of the release medium had an effect on the drug release from AL beads, and a long-term hypoglycemic effect was observed in diabetic rats after oral administration of AL- and AL-CS- beads. The ALand AL-CS-beads shrunk after freeze-drying, which is similar to the results reported by ZoharPerez et al [30]. There was a slight but insignificant difference between particle sizes of the blank and drug-loaded AL and AL-CS beads, indicating that the presence of chitosan and incorporation of metformin $\mathrm{HCl}$ into the beads did not influence the particle size. This observation is in a good agreement with the results of Rajendran and Basu, who reported that size of AL-beads was not significantly enhanced by the addition of chitosan to the formulation [11]. The low $E E \%$ values obtained for the beads might be due to the high solubility of metformin $\mathrm{HCl}$ in water resulting in drug leakage to the aqueous medium. Similar observation was also made by Ramteke et al [31]. These authors reported low encapsulation efficiency (about $25 \%$ ) for metformin $\mathrm{HCl}$-loaded alginate beads prepared using $\mathrm{CaCl}_{2}$, an observation attributed to the high aqueous solubility of drug [31].

All drug release profiles displayed a biphasic release pattern characterized by an initial fast release (burst effect), followed by a slower release rate. The initial burst release is attributable to the high water solubility of the drug and its adsorption to the surface of the beads. In addition, although drug release from the AL-CS beads were very similar in both release media (28 vs. $27 \%$ for $\mathrm{pH} 6.8$ and $\mathrm{pH} 1.2$ in the first hour), drug release from the AL beads seemed to be influenced slightly by the $\mathrm{pH}$ of the medium. The $\mathrm{pH}$ of the release medium affects the swelling of $A L$ beads and the drug release from $\mathrm{AL}$ beads. In an acidic release medium, the reduction in the electrostatic repulsion due to the formation of $\mathrm{COOH}$ groups and intermolecular hydrogen bond results in the restriction of the relaxation of polymer chains and formation of more compact network and thereby reducing drug release. It was observed that the degree of swelling of $A L$ beads increased with increase of $\mathrm{pH}$ of release medium, probably due to exchange of the $\mathrm{Ca}^{2+}$ ion with $\mathrm{Na}^{+}$. These results are in agreement with the results of previous studies $[11,15]$. 


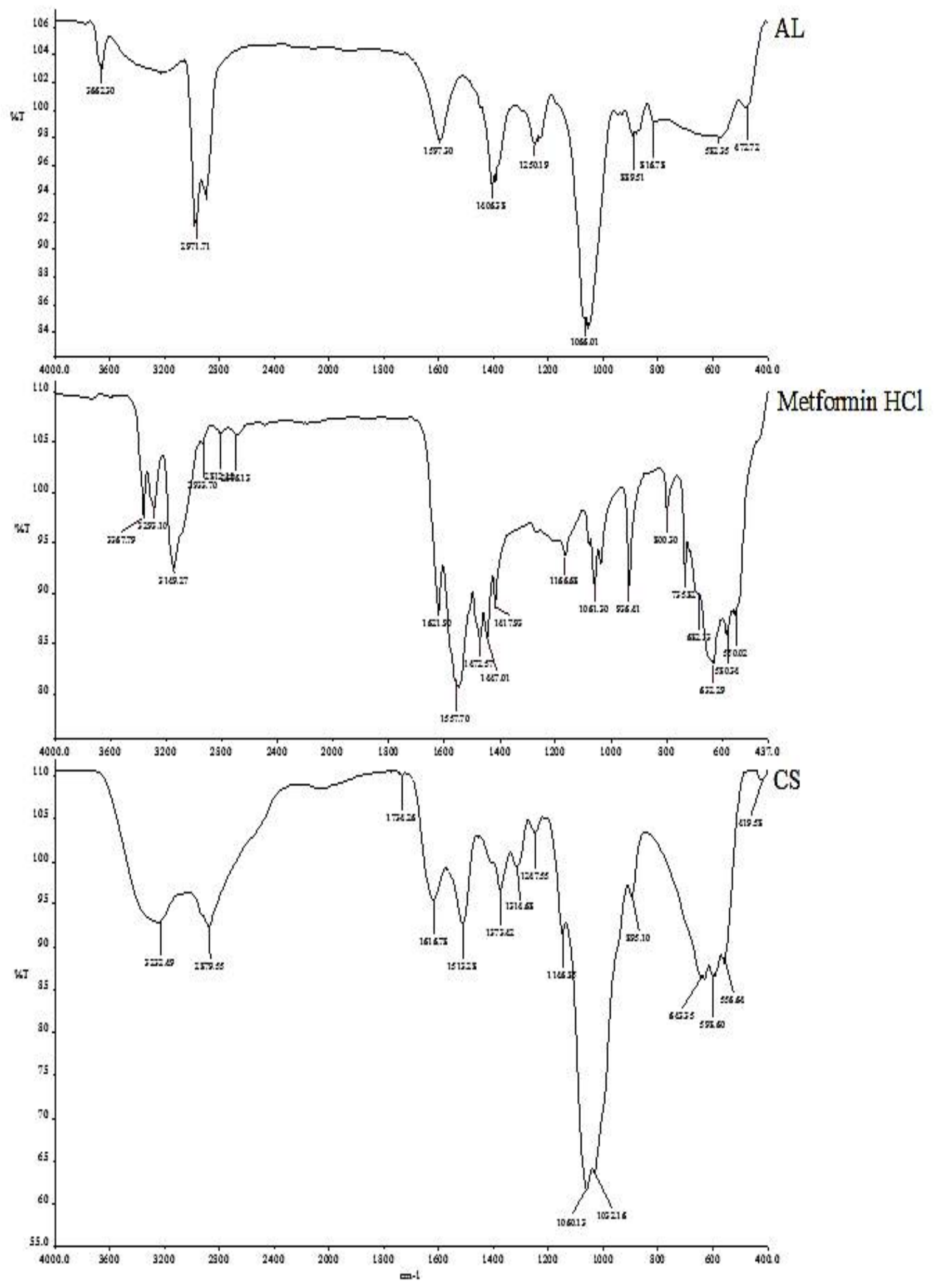

Figure 3: $\mathrm{FT}-\mathrm{IR}$ spectra of $\mathrm{AL}$, metformin $\mathrm{HCl}$ and $\mathrm{CS}$ 

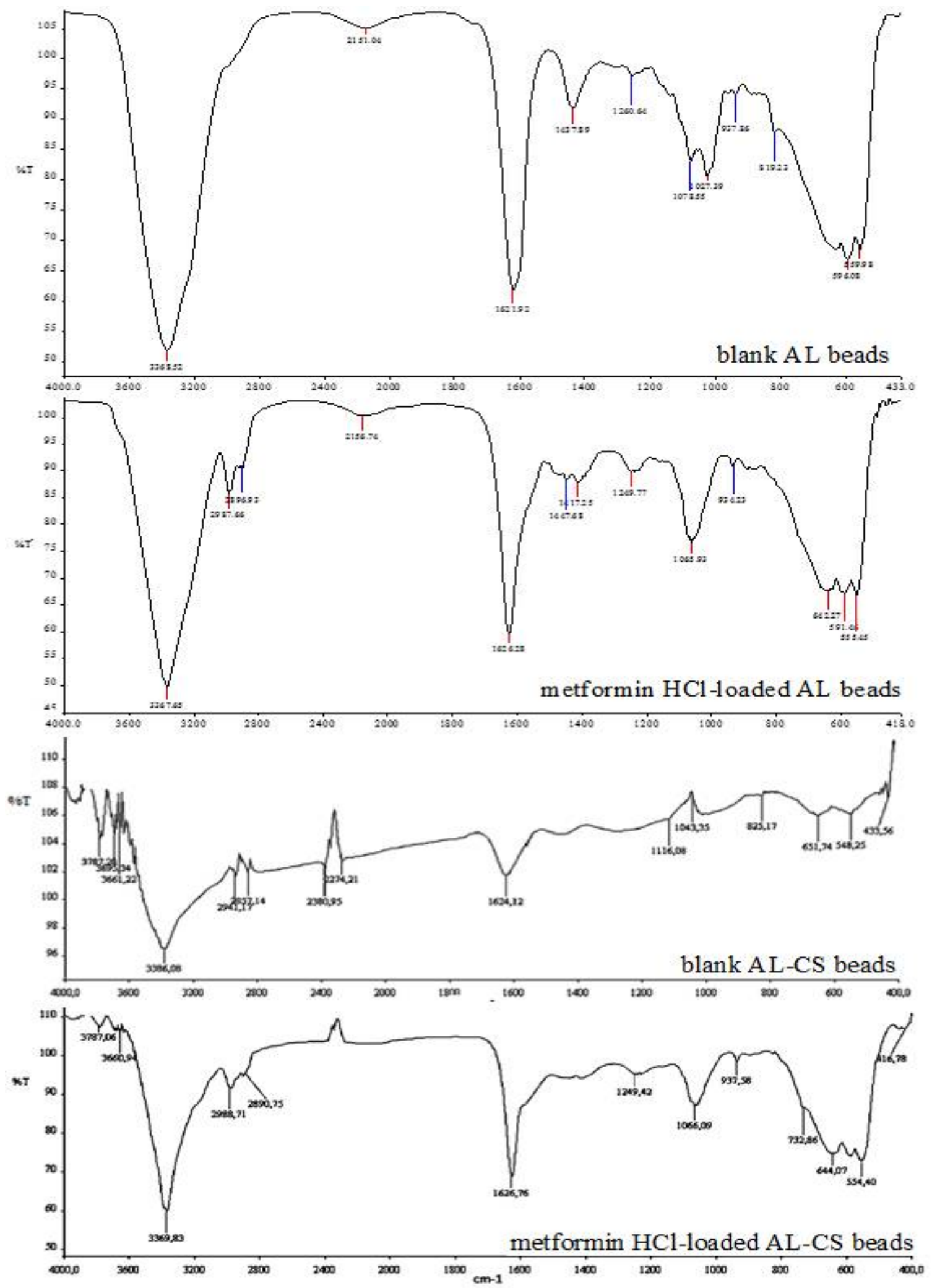

Figure 4: FT-IR spectra of blank alginate beads, metformin $\mathrm{HCl}$-loaded alginate beads, blank alginate-chitosan beads, metformin $\mathrm{HCl}$-loaded alginate-chitosan beads 


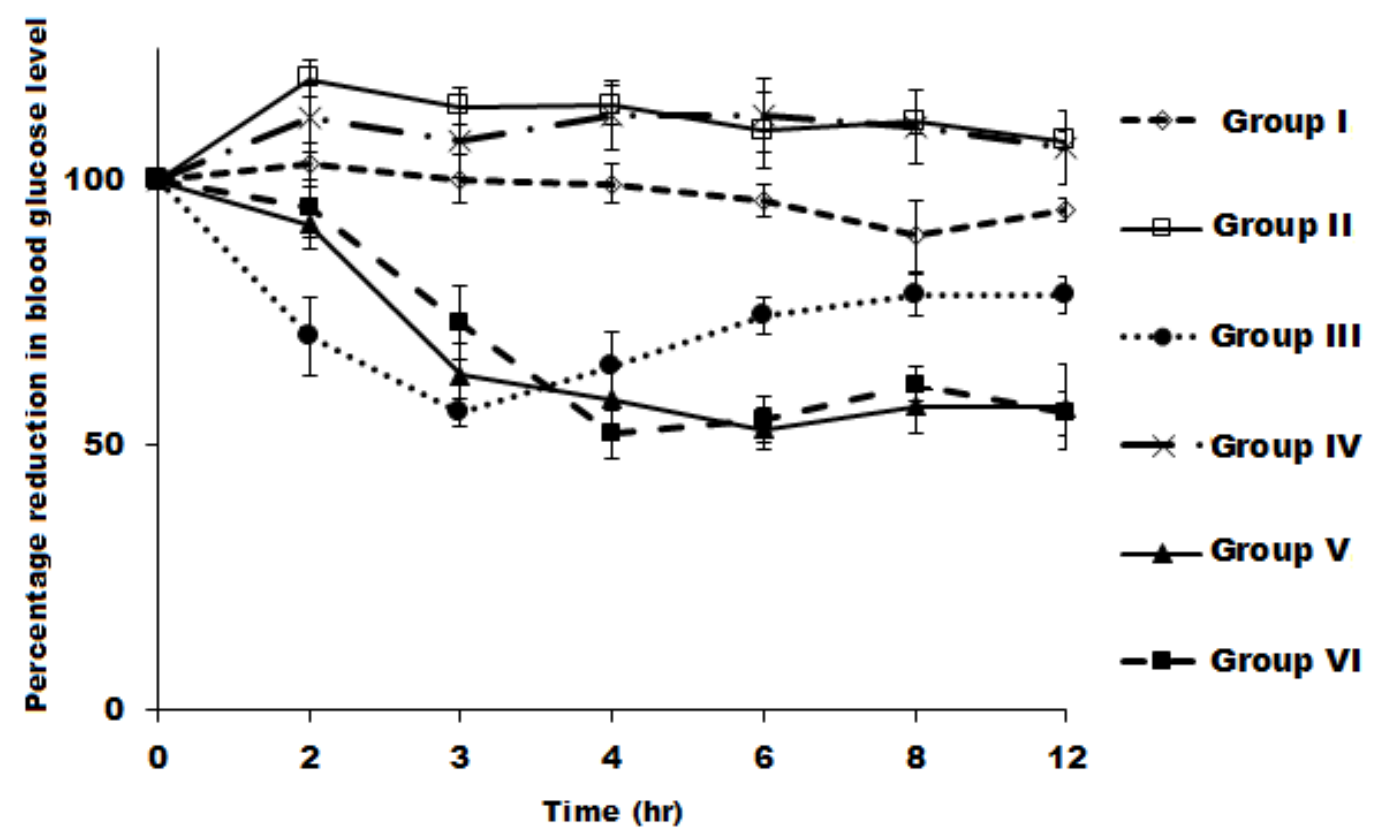

Figure 5: Blood glucose level (\%) of rats (at $12 \mathrm{hr}$ after treatments) in streptozotocin-nicotinamideinduced diabetic rats after oral administration of metformin $\mathrm{HCl}$-loaded alginate and alginate-chitosan beads and pure metformin HCl (Mean $\pm \mathrm{SD}$ ). Note: Group I: Control rats ( $n=6)$; Group II: Diabetic control (n=8); Group III: Diabetic rats treated with pure metformin $\mathrm{HCl}(n=6)$; Group IV: Diabetic rats treated with blank beads ( $n=8)$; Group V: Diabetic rats treated with metformin $\mathrm{HCl}$-loaded alginatechitosan beads ( $n=9$ ); Group VI: Diabetic rats treated with metformin $\mathrm{HCl}$-loaded AL beads $(n=6)$

Various approaches (chemicals, dietary manipulation, or surgery) are available in the literature for development of experimentallyinduced type 2 diabetes. For this purpose, we used STZ-nicotinamide. STZ taken up by pancreatic $\beta$-cells via GLUT2 (the glucose transporter) increases the production of free radicals and consequently causes impaired insulin secretion due to reduced insulin synthesis in $\beta$-cells and also the death of $\beta$-cells. On the other hand, nicotinamide prevents the STZinduced cytotoxicity. Tahara et al [22] reported that co-administration of nicotinamide $(100 \mathrm{mg} / \mathrm{kg}$ b.w.) and streptozotocin (50 mg/kg b.w.) was successful in inducing mild diabetes in rats. Reduction in the fasting blood glucose level by the pure drug was obtained for $3 \mathrm{hr}$ and the level restored after $3 \mathrm{hr}$. On the other hand, the fasting blood glucose levels of metformin $\mathrm{HCl}$-loaded AL-CS and AL beads gradually declined and peaked in $6 \mathrm{hr}$ and $4 \mathrm{hr}$, respectively, indicating that hypoglycaemic effect was extended by both bead formulations. Similar observations are reported in the literature [15,32]. Nayak et al [15] evaluated the hypoglycaemic effects of nonfloating and floating alginate beads containing metformin $\mathrm{HCl}$ on STZ-induced diabetic rats and found that a significant hypoglycaemic effect was obtained for floating beads 3 to $9 \mathrm{hr}$ after bead administration. However, this effect was visible up to $5 \mathrm{hr}$ after the administration of non-floating beads. Thus, floating beads were more useful for sustained hypoglycaemic effect, and a $25 \%$ reduction in the blood glucose level was considered as significant hypoglycaemic effect. Similarly, following administration of metformin $\mathrm{HCl}$-loaded fenugreek seed mucilage alginate muco-adhesive beads (equivalent to $100 \mathrm{mg} / \mathrm{kg}$ metformin $\mathrm{HCl}$ ) to alloxan-induced diabetic rats, a significant hypoglycaemic effect was demonstrated up to $10 \mathrm{hr}$, and about $30 \%$ reduction in blood glucose level was obtained during this period [32]. These results support our observation with regard to the prolonged hypoglycaemic effect obtained with metformin $\mathrm{HCl}$-loaded AL and AL-CS beads.

\section{CONCLUSION}

This study shows that $\mathrm{HCl}$-loaded $\mathrm{AL}$ and AL-CS bead formulations may be useful in prolonging the hypoglycaemic effect of orally administered metformin. This is capable of increasing patient compliance with the medication. Further are, however, needed to explore the degree of side effect reduction of the formulated metformin.

\section{DECLARATIONS}

\section{Acknowledgement}

This study was supported by Ataturk University Research Foundation - project number:2013/057. 


\section{Conflict of Interest}

No conflict of interest associated with this work.

\section{Contribution of Authors}

The authors declare that this work was done by the authors named in this article and all liabilities pertaining to claims relating to the content of this article will be borne by them.

\section{Open Access}

This is an Open Access article that uses a funding model which does not charge readers or their institutions for access and distributed under the terms of the Creative Commons Attribution License (http://creativecommons.org/licenses/by 14.0) and the Budapest Open Access Initiative (http://www.budapestopenaccessinitiative.org/rea d), which permit unrestricted use, distribution, and reproduction in any medium, provided the original work is properly credited.

\section{REFERENCES}

1. Sweetman $S(E d)$, The Martindale: The Complete Drug Reference. London: Pharmaceutical Press, Electronic version, 2007.

2. Cetin M, Sahin S. Microparticulate and nanoparticulate drug delivery systems for metformin hydrochloride. Drug Deliv, 23(8): 2796-2805.

3. Viollet B, Guigas B, Sanz Garcia N, Leclerc J, Foretz M, Andreeli F. Cellular and molecular mechanisms of metformin: an overview. Clin Sci (Lond), 2012; 122(6): 253-270.

4. Dowling RJ, Goodwin PJ, Stambolic V. Understanding the benefit of metformin use in cancer treatment. BMC Med, 2011; 9: 33, doi: 10.1186/1741-7015-9-33.

5. Corti G, Cirri M, Maestrelli F, Mennini N, Mura $P$. Sustained-release matrix tablets of metformin hydrochloride in combination with triacetyl $\beta$ cyclodextrin. Eur J Pharm Biopharm, 2008; 68(2): 303309.

6. Adikwu MU, Yoshikawa Y, Takada K. Bioadhesive delivery of metformin using prosopis gum with antidiabetic potential. Biol Pharm Bull, 2003; 26(5): 662666.

7. Murphy C, Pillay V, Choonara YE, du Toit LC, Ndesendo VM, Chirwa N, Kumar P. Optimization of a dual mechanism gastrofloatable and gastroadhesive delivery system for narrow absorption window drugs. AAPS PharmSciTech, 2012; 13(1): 1-15.

8. Marathe $P H$, Wen $Y$, Norton J, Greene DS, Barbhaiya $R H$, Wilding IR. Effect of altered gastric emptying and gastrointestinal motility on metformin absorption. $\mathrm{Br} J$ ClinPharmacol, 2000; 50(4): 325-332.
9. Silva $C M$, Ribeiro AJ, Fiqueiredo IV, Gonçalves AR, Veiga F. Alginate microspheres prepared by internal gelation: Development and effect on insulin stability. Int J Pharm, 2006; 311(1-2): 1-10.

10. Bhattarai RS, Dhandapani NV, Shrestha A. Drug delivery using alginate and chitosan beads: An overview. Chron Young Sci 2011; 2(4): 192-196.

11. Rajendran A, Basu SK. Alginate-chitosan particulate system for sustained release of nimodipine. Trop $J$ Pharm Res, 2009; 8(5): 433-440.

12. Patel MP, Patel RR, Patel JK. Chitosan mediated targeted drug delivery system: A review. J Pharm Pharmaceut Sci 2010; 13(4): 536-557.

13. Agnihotri SA, Mallikarjuna NN, Aminabhavi TM. Recent advances on chitosan-based micro- and nanoparticles in drug delivery. J Control Release 2004; 100(1): 5-28.

14. Nafady MM, Attalla KM, Sayed MA. Formulation and evaluation of extended release metformin hydrochloride beads. Int J Pharm Pharm Sci, 2014; 6: 433-441.

15. Nayak A, Jain SK, Pandey RS. Controlling release of metformin $\mathrm{HCl}$ through incorporation into stomach specific floating alginate beads. Mol Pharm, 2011; 8(6): 2273-2281.

16. Mandal S, Kumar SS, Krishnamoorthy B, Basu SK. Development and evaluation of calcium alginate beads prepared by sequential and simultaneous methods. Braz J Pharm Sci,2010; 46(4): 785-793.

17. Rajalakshmi G, Dhulipati R, Damodharan N. Design and characterization of ambroxol hydrochloride sustained release microbeads. IJBPR 2013; 4(9): 655-662.

18. Rasool BK, Fahmy SA. Development of coated beads for oral controlled delivery of cefaclor: In vitro evaluation. Acta Pharm 2013; 63(1): 31-44.

19. Mujtaba A, Ali M, Kohli K. Formulation of extended release cefpodoximeproxetil chitosan-alginate beads using quality by design approach. Int J Biol Macromol 2014; 420-429, doi: 10.1016/j.ijbiomac.2014.05.066.

20. Gundogdu N, Cetin M. Chitosan-poly (lactide-coglycolide) (CS-PLGA) nanoparticles containing metformin $\mathrm{HCl}$ : preparation and in vitro evaluation. Pak J Pharm Sci, 2014; 27(6): 1923-1929.

21. Bisht $R$, Bhattacharya $S$. Effect of various extracts of Desmodiumgangeticumon Streptozotocin-nicotinamide induced type-2 diabetes. Asian J Plant Sci Res 2013; 3(3): 28-34.

22. Tahara A, Matsuyama-Yokono A, Nakano R, Someya $Y$, Shibasaki M. Hypoglycaemic effects of antidiabetic drugs in streptozotocin-nicotinamide-induced mildly diabetic and streptozotocin-induced severely diabetic rats. Basic Clin Pharmacol Toxicol 2008; 103(6): 560568.

23. Barik R, Jain S, Qwatra D, Joshi A, Tripathi GS, Goyal R. Antidiabetic activity of aqueous root extract of Ichnocarpus frutescens in streptozotocin-nicotinamide induced type-ll diabetes in rats. Indian J Pharmacol 2008; 40(1): 19-22.

24. Daemi H, Barikani M. Synthesis and characterization of calcium alginate nanoparticles, sodium

Trop J Pharm Res, February 2017; 16(2): 295 
homopolymannuronate salt and its calcium nanoparticles. Sci Iran 2012; 19(6): 2023-2028.

25. Banerjee $P$, Deb J, Roy A, Ghosh A, Chakraborty $P$. Fabrication and development of pectin microsphere of metformin hydrochloride. ISRN Pharm 2012; 230621: 17 doi:10.5402/2012/230621.

26. Gunasekaran S, Natarajan RK, Renganayaki V, Natarajan S. Vibrational spectra and thermodynamic analysis of metformin. Indian J Pure Appl Phys 2006; 44(7): 495-500.

27. Gonil P, Sajomsang W, Ruktanonchai UR, Pimpha N, Sramala I, Nuchuchua O, Saesoo S, Chaleawlertumpon $S$, Puttipipatkhachorn $S$. Novel quaternized chitosan containing $\beta$-cyclodextrin moiety: Synthesis, characterization and antimicrobial activity. Carbohydr Polym, 2011; 83(2): 905-913.
28. Mourya VK, Inamdar NN, Tiwari A. Carboxymethyl chitosan and its applications. Adv Mater Lett 2010; 1(1): 11-33.

29. Salehizadeh H, Hekmatian E, Sadeghi M, Kennedy K. Synthesis and characterization of core-shell $\mathrm{Fe}_{3} \mathrm{O}_{4}$-goldchitosan nanostructure. J Nanobiotechnology, 2012; 10: 3, doi:10.1186/1477-3155-10-3

30. Zohar-Perez C, Chet I, Nussinovitch A. Irregular textural features of dried alginate-filler beads. Food Hydrocoll 2004; 18(2): 249-258.

31. Ramteke KH, Vansola JB, Tailor DJ, Parmar JR. Formulation and evaluation of metformin hydrochloride beads by ionotropic gelation technique. JPSI, 2012; 1(1):75-78.

32. Nayak AK, Pal D, Pradhan J, Hasnain MS. Fenugreek seed mucilage-alginate mucoadhesive beads of metformin HCl: Design, optimization and evaluation. Int J Biol Macromol 2013; 54: 144-154. 